\title{
VEGF Polymorphisms Related to Higher Serum Levels of Protein Identify Patients with Hepatocellular Carcinoma
}

\author{
Maria Eduarda Lopes Baitello, ${ }^{1}$ Graciele Domitila Tenani, ${ }^{1}$ \\ Rafael Fernandes Ferreira, ${ }^{1}$ Victor Nogueira, ${ }^{1}$ Marcela Augusta de Souza Pinhel, ${ }^{1}$ \\ Rita de Cássia Martins Alves da Silva, ${ }^{2}$ Renato Ferreira da Silva, ${ }^{3}$ Patrícia da Silva Fucuta, ${ }^{2}$ \\ Moacir Fernandes de Godoy, ${ }^{1}$ and Dorotéia Rossi Silva Souza ${ }^{1}$
}

\author{
${ }^{1}$ Research Centre for Biochemistry and Molecular Biology, Medical School of São José do Rio Preto (FAMERP), \\ São José do Rio Preto, SP, Brazil \\ ${ }^{2}$ Hepatology Unit, HB University Medical Centre, FUNFARME/FAMERP, São José do Rio Preto, SP, Brazil \\ ${ }^{3}$ Liver Transplantation Unit, HB University Medical Centre, FUNFARME/FAMERP, São José do Rio Preto, SP, Brazil
}

Correspondence should be addressed to Maria Eduarda Lopes Baitello; duda_lps@hotmail.com

Received 18 February 2016; Revised 10 July 2016; Accepted 4 August 2016

Academic Editor: Aldo J. Montano-Loza

Copyright (C) 2016 Maria Eduarda Lopes Baitello et al. This is an open access article distributed under the Creative Commons Attribution License, which permits unrestricted use, distribution, and reproduction in any medium, provided the original work is properly cited.

\begin{abstract}
Hepatocellular carcinoma (HCC) is the most common primary neoplasia of the liver. Major risk factors for hepatocellular carcinoma include chronic liver diseases, carcinogenic agents, and genetic alterations as well as vascular endothelial growth factor (VEGF) involved in angiogenesis process. The aim of this study was to evaluate the association of VEGF-A (C936T and A1154G) with HCC and cirrhosis, in addition to serum levels of VEGF, clinical profile, lifestyle habits, and comorbidities. A total of 346 individuals were studied: 102 with HCC (G1), 117 with cirrhosis (G2), and 127 controls (G3). Polymorphisms were analysed by PCR/RFLP and serum levels of VEGF by ELISA. Alpha error was set at 5\%. The wild-type genotype of both polymorphisms prevailed $(P>0.05)$. In G1, 23\% of the patients died, with no relation to genetic profile $(P>0.05)$. Increased VEGF level was observed in G1 and G3, related to the mutant allele of VEGF-C936T and VEGF-A1154G, respectively, and compared with the wild-type genotype $(P=0.0285$; $P=0.0284$, resp.) as well as G1 versus G2 and G3 for VEGF-C936T and G1 versus G2 for VEGF-A1154G ( $P<0.05$ for both). In conclusion, there is a relationship between mutant alleles of VEGF-C936T and VEGF-A1154G polymorphisms and higher VEGF level, making them potential markers for HCC.
\end{abstract}

\section{Introduction}

Hepatocellular carcinoma (HCC) is the most common primary neoplasia of the liver, with increasing incidence and mortality [1]. In this context, emphasis should be given to Africa and especially to Asia, as China accounts for approximately $50 \%$ of world's HCC cases [2]. On the other hand, there is low incidence of the disease in North America and South America as well as in Europe [3]. High mortality is mainly due to the lack of follow-up on patients with chronic liver disease [4]. Imaging techniques, such as ultrasound, computed tomography, and magnetic resonance, are used for the diagnosis of the disease. In cases where $\mathrm{X}$-ray exams have produced inconclusive results, histology is considered the gold standard [5].
HCC is a solid and well-vascularized malignant tumour, which usually develops from a chronic liver disease, being the cirrhosis responsible for $80-90 \%$ of cases. Hepatitis B virus (HBV) and $\mathrm{C}$ virus ( $\mathrm{HCV}$ ), alcohol consumption, smoking, and exposure to aflatoxins are also associated with an increased risk of developing the disease. Recently, the incidence of HCC has grown by hepatic steatosis [69]. Hepatocarcinogenesis can also result from the combination of genetic and epigenetic alterations in multiple signalling pathways, which affect cell proliferation, angiogenesis, cell invasion, and vascular permeability, leading to metastasis [10].

Neovascularization is an important mechanism in the pathogenesis of HCC because it contributes to the transition 
from dysplastic liver nodules into malignant phenotype [11]. In this context, the vascular endothelial growth factor-A (VEGF-A) has been reported as an important angiogenic factor in developing HCC [12]. The VEGF family consists of four VEGF genes (A-D) located in the human chromosome 6p21.3, which encode proteins that activate multiple signalling networks and promote endothelial cell growth, migration, differentiation, and control of vascular permeability $[13,14]$.

Studies show that VEGF-A polymorphisms are associated with an alteration in the promoter and $3^{\prime}$-UTR region of the gene, reflecting changes in plasma levels of the protein $[15$, 16]. VEGF-C936T and VEGF-A114G were related to changes in plasma levels of the protein in several studies on solid tumours, but the results are controversial [17-19]. However, studies that correlate between polymorphisms of VEGF and HCC are rare, usually with small numbers of patients as well as a few polymorphisms $[16,20]$.

Moreover, within the limits of our knowledge, there are no studies in the literature involving polymorphisms of VEGF and HCC in Brazilian casuistic of interbred character, which contributed to the choice of these polymorphisms in this study.

Therefore, this study evaluated the association of VEGFA polymorphisms (C936T and A1154G) with cirrhosis, HCC, and respective clinical classification, in addition to serum levels of VEGF and survival in HCC. It also considered risk factors for the disease, including comorbidities and lifestyle habits.

\section{Methods}

2.1. Materials. This case-control study included 346 individuals treated at the Hepatology Unit of Hospital de Base University Medical Centre (HB) at the Medical School of São José do Rio Preto (FAMERP). They were divided into three groups: G1, 102 patients with HCC; G2, 117 patients with cirrhosis; G3, 127 individuals without the disease (controls). The patients were classified according to the staging system set by Barcelona Clinic Liver Cancer (BCLC) in G1. Control subjects were selected at the Blood Centre at HB/FAMERP and were tested for blood-borne infections [21], including $\mathrm{HBV}$ and HCV. All participants were informed of the study and signed an Informed Consent Document. The project was approved by the Research Ethics Committee, CEP/FAMERP (protocol number: 6910/2011).

2.2. Genotyping. Genomic DNA was extracted from leukocytes of the total peripheral blood with EDTA using salting-out method [22]. The genotyping was performed by PCR/RFLP (polymerase chain reaction/restriction fragments length polymorphism) with a final volume of $25 \mu \mathrm{L}$ for the reactions as follows: $12.55 \mu \mathrm{L}$ of sterile MilliQ water, $2.5 \mu \mathrm{L}$ of DMSO (dimethyl sulfoxide), $2.5 \mu \mathrm{L}$ of $10 \mathrm{x}$ PCR buffer, $1.25 \mu \mathrm{L}$ of DNTP mix $(10 \mathrm{mM})$ (deoxyribonucleotide triphosphate mix), $1.25 \mu \mathrm{L}$ of $\mathrm{P} 1$ primer $(10 \mathrm{pmol} / \mu \mathrm{L}), 1.25 \mu \mathrm{L}$ of $\mathrm{P} 2$ primer $(10 \mathrm{pmol} / \mu \mathrm{L}), 1.5 \mu \mathrm{L}$ of $\mathrm{MgCl}_{2}(25 \mathrm{mM}), 1 \mathrm{U}$ of Taq DNA polymerase (Thermo Scientific, Thermo Fisher Scientific,
Inc., Massachusetts, USA), and 100 ng of DNA. PCR was performed under the following conditions: 5 minutes at $95^{\circ} \mathrm{C}$, followed by 35 cycles at $95^{\circ} \mathrm{C}$ for 45 seconds, $61^{\circ} \mathrm{C}$ for 45 seconds, $72^{\circ} \mathrm{C}$ for 45 seconds, and finally at $72^{\circ} \mathrm{C}$ for 7 minutes. The primers used for genotyping were $\mathrm{F}^{\prime}$ TAAATGTATGTATGTGGGTGGGTGTGTCACAGG-3' and R5 ${ }^{\prime}$-AAGGAAGAGGAGACTCTGCGCAGAGC-3' for VEGF-C936T and $\mathrm{F}^{\prime}$-TCCTGCTCCCTCCTCGCCAATG$3^{\prime}$ and R5'-GGCGGGGACAGGCGAGCATC-3' for VEGFA1154G. The amplification product was subjected to enzyme restriction with NlaIII (VEGF-C936T) and MnlI (VEGFA1154G), followed by staining with GelRed (Uniscience, São Paulo, Brazil) and agarose gel electrophoresis of $2.5 \%$ and $4 \%$, respectively. C-alleles (208 base pairs-bp) and T-alleles (122 bp and $86 \mathrm{bp}$ ) were identified for VEGF-C936T, and Aalleles (184 bp and $22 \mathrm{bp}$ ) and G-alleles (150 bp, $34 \mathrm{bp}$, and $22 \mathrm{bp}$ ) were identified for $V E G F-A 1154 G$.

Serum VEGF levels were obtained using ELISA (enzymelinked immunosorbent assays, R \& D System, Inc., Minneapolis, USA), in compliance with the manufacturer's instructions. For qualitative analysis, the reference value was set at $186.7 \mathrm{pg} / \mathrm{mL}$, obtained by the cut-off value of the receiver operating characteristic curve (ROC).

The clinical classification of the patients was made based on the BCLC (A, B, C, or D) and Child-Pugh staging system (A, B, or C) according to the clinical practice guidelines of the American Association for the Study of Liver Diseases [5]. Patients classified as B and C of BCLC have been grouped due to the lack of portal invasion and/or metastasis of data from medical records of patients.

2.3. Statistical Analysis. The comparative analyses of allele frequencies and genotype distributions among the groups, as well as of further qualitative variables, were performed using the Chi-Square test with Yates correction or Fisher's exact test. Statistical models used for genetic profile analysis were dominant, recessive, and heterozygous. For the analysis of the Hardy-Weinberg equilibrium (HW), Chi-Square test was applied. Survival was analysed by Kaplan-Meier method and the results were compared by the log rank test. Quantitative variables were analysed using the MannWhitney test (within groups) and Kruskal-Wallis (between groups). For the evaluation of sensitivity, specificity, positive predictive value, and negative predictive value, the ROC curve was used, considering areas under the curve $\geq 0.7$ as clinically relevant. A box-plot graphical representation was used, including minimum, interquartile range, median, and maximum values, as well as possible outliers. Alpha error was set at $5 \%$. The programs used in the analyses were Minitab, Stats Direct, and GraphPad.

\section{Results}

Demographic profiles, lifestyle habits, comorbidities, and clinical classification of patients are shown in Table 1. Men accounted for $75 \%$ of subjects in all groups $(P<0.05)$. There was a higher frequency of alcohol in both groups of patients, G1 (56\%) and G2 (50\%), compared with controls (13\%) $(P<$ 
TABLE 1: Demographic profile, lifestyle, risk factors, and clinical classification in patients with hepatocellular carcinoma (G1), cirrhosis (G2), and individuals without the disease (G3).

(a)

\begin{tabular}{|c|c|c|c|c|c|c|c|c|c|}
\hline \multirow{2}{*}{ Variable } & \multicolumn{2}{|c|}{$\mathrm{Gl}(N=102)$} & \multicolumn{2}{|c|}{$\mathrm{G} 2(N=117)$} & \multicolumn{2}{|c|}{$\mathrm{G} 3(N=127)$} & \multicolumn{3}{|c|}{$P^{*}$ value } \\
\hline & $N$ & $(\%)$ & $N$ & $(\%)$ & $N$ & $(\%)$ & $\mathrm{G} 1 \times \mathrm{G} 3$ & $\mathrm{G} 2 \times \mathrm{G} 3$ & $\mathrm{G} 1 \times \mathrm{G} 2$ \\
\hline \multicolumn{10}{|l|}{ Gender } \\
\hline Female & 25 & (25) & 29 & $(25)$ & 32 & $(25)$ & \multirow{2}{*}{0.904} & \multirow{2}{*}{0.941} & \multirow{2}{*}{0.962} \\
\hline Male & 77 & (75) & 88 & (75) & 95 & (75) & & & \\
\hline \multicolumn{10}{|l|}{ Lifestyle } \\
\hline Alcohol consumption & 57 & (56) & 58 & $(50)$ & 18 & (13) & $<0.0001$ & $<0.0001$ & 0.42 \\
\hline Smoking & 51 & (50) & 40 & $(34)$ & 30 & $(21)$ & $<0.0001$ & 0.0927 & 0.0257 \\
\hline \multicolumn{10}{|l|}{ Comorbidity } \\
\hline HBV & 21 & (21) & 12 & $(10)$ & & & & & 0.0521 \\
\hline $\mathrm{HCV}$ & 51 & (50) & 57 & $(49)$ & & & & & 0.957 \\
\hline Cirrhosis & 86 & $(84)$ & 117 & $(100)$ & & & & & \\
\hline
\end{tabular}

(b)

\begin{tabular}{lcc}
\hline Clinical classification & \multicolumn{2}{c}{$\mathrm{G} 1(N=89)$} \\
\hline BCLC & $N$ & $(\%)$ \\
$\mathrm{A}$ & 28 & $(31)$ \\
$\mathrm{B} / \mathrm{C}$ & 52 & $(59)$ \\
$\mathrm{D}$ & 9 & $(10)$ \\
\hline
\end{tabular}

*Fisher's exact test or Chi-Square test; $N$ = number of subjects; HBV = hepatitis B virus; HCV = hepatitis C virus; BCLC = Barcelona Clinic Liver Cancer.

0.0001 for G1 versus G3 and G2 versus G3) while G1 versus G2 did not show significance $(P=0.425)$. Yet, smoking prevailed in G1 (50\%), compared with G2 (34\%; $P=0.0257)$ and G3 (21\%; $P<0.0001)$, while G2 versus G3 did not show significance $(P=0.0927)$. G1 showed higher frequency of cirrhosis (84\%), followed by HCV (50\%) and HBV (21\%), and the same occurred for G2 (49\% and $10 \%)$ with no significant difference between the groups $(P=0.957$ and $P=0.052$, resp.). The clinical classification of BCLC was performed in 89 patients in G1, with $31 \%$ belonging to the A classification, $59 \%$ to $\mathrm{B}$ or $\mathrm{C}$, and $10 \%$ to $\mathrm{D}$.

Table 2 shows the VEGF-A polymorphisms. The wildtype homozygous genotype for C936T (C/C) prevailed in $\mathrm{G} 1$ (71\%), G2 (72\%), and G3 (71\%) as well as the wild-type allele $(\mathrm{C}=0.85)$ in all groups. For the A1154G polymorphism, the wild-type genotype $(\mathrm{G} / \mathrm{G})$ also prevailed in all groups $(60 \%$, $51 \%$, and $57 \%$, resp.) as well as the wild-type allele ( $\mathrm{G}=0.77$; $0.74 ; 0.76$, resp.), with no significant difference between the groups $(P>0.05)$. HW equilibrium for both polymorphisms was observed in all groups $(P>0.05)$.

Figure 1 shows the association between $V E G F-A$ polymorphisms and survival of patients with HCC after 36 months of diagnosis. For VEGF-C936T, this study considered the heterozygous genotype $(\mathrm{C} / \mathrm{T})$ versus wild-type homozygous genotype $(\mathrm{C} / \mathrm{C})$, since homozygous mutant genotypes could not be found in the sample. Among patients, 72 (71\%) had genotype C/C, of whom 14 (19\%) died, with survival of $56.2 \pm 10.9 \%$ in 36 months. For the C/T genotype, 9 of 30 patients $(30 \%)$ died, with survival of $49.5 \pm 13.8 \%$ in 36 months $(P=0.582)$. For VEGF-A1154G, the dominant statistical model $\left(\_/ A \times G / G\right)$ was considered. Among $61(60 \%)$ patients with G/G genotype, 11 (18\%) died, corresponding to survival of $60.8 \pm 11.3 \%$ in 36 months of follow-up. As for the genotype _/A, 12 (29\%) of 41 patients died, with survival rate of $48.3 \pm 12.1 \%$ in 36 months $(P=0.186)$.

Table 3 shows the relationship between polymorphisms with BCLC clinical classifications in G1. The wild-type alleles and genotypes for both polymorphisms prevailed in all classifications, with no statistical difference $(P>0.05)$. Increased serum levels of VEGF (Figure 2) were observed in G1 (264.8 pg/mL), compared with G2 and G3 $(182.8 \mathrm{pg} / \mathrm{mL}$; $182.2 \mathrm{pg} / \mathrm{mL})(P=0.0007$ for G1 versus $\mathrm{G} 2$ and $P=0.0026$ for G1 versus G3). Yet, serum levels of G2 versus G3 showed no significant differences. Serum VEGF levels were also analysed according to the genetic profile (Table 4). In HCC patients (G1), the elevated serum levels were related to the mutant allele (T) of VEGF-C936T (430.0 pg/mL), compared with the wild-type genotype $(\mathrm{C} / \mathrm{C})(250.5 \mathrm{pg} / \mathrm{mL} ; P=0.0285)$. G1 also showed elevated serum levels when compared to G2 $(173.5 \mathrm{pg} / \mathrm{mL})$ and G3 $(113.9 \mathrm{pg} / \mathrm{mL})(P=0.0038)$ in an intergroup analysis with Kruskal-Wallis test. In relation to VEGF-A1154G, the serum levels of VEGF were increased in controls with the mutant allele $\left({ }_{-} / \mathrm{A}=185.2 \mathrm{pg} / \mathrm{mL}\right)$ compared with genotype G/G (182.2 pg/mL; $P=0.0284)$. The comparative analysis also showed a significant increase in serum levels of VEGF in the presence of the mutant allele in G1 $(297.8 \mathrm{pg} / \mathrm{mL})$ compared to $\mathrm{G} 2(183.3 \mathrm{pg} / \mathrm{mL} ; P=0.0069)$, while G1 versus G3 and G2 versus G3 did not represent statistical differences.

Predictive analysis of serum VEGF levels in the presence of the mutant allele was performed for both polymorphisms (Figure 3). For the VEGF-C936T, comparison of G1 versus 
TABLE 2: Allelic and genotypic frequencies of VEGF-C936T and VEGF-A1154G polymorphisms in patients with hepatocellular carcinoma (G1), cirrhosis (G2), and individuals without the disease (G3).

(a) C936T

\begin{tabular}{|c|c|c|c|c|c|c|c|c|c|}
\hline \multirow[b]{2}{*}{ Allele } & \multicolumn{2}{|c|}{$\mathrm{G} 1(N=102)$} & \multicolumn{2}{|c|}{$\mathrm{G} 2(N=117)$} & \multicolumn{2}{|c|}{$\mathrm{G} 3(N=217)$} & \multirow{2}{*}{$\mathrm{G} 1 \times \mathrm{G} 3$} & \multicolumn{2}{|l|}{$P^{*}$ value } \\
\hline & $n$ & $\mathrm{AF}$ & $n$ & $\mathrm{AF}$ & $n$ & $\mathrm{AF}$ & & & \\
\hline $\mathrm{C}$ & 174 & 0.85 & 199 & 0.85 & 217 & 0.85 & \multirow{2}{*}{0.966} & \multirow{2}{*}{0.903} & \multirow{2}{*}{0.941} \\
\hline $\mathrm{T}$ & 30 & 0.15 & 35 & 0.15 & 37 & 0.15 & & & \\
\hline Genotype & $N$ & $(\%)$ & $N$ & $(\%)$ & $N$ & $(\%)$ & & & \\
\hline \multicolumn{10}{|l|}{ Dominant } \\
\hline $\mathrm{C} / \mathrm{C}$ & 72 & $(71)$ & 84 & $(72)$ & 90 & $(71)$ & \multirow{2}{*}{0.963} & \multirow{2}{*}{0.985} & \multirow{2}{*}{0.962} \\
\hline $\mathrm{C} / \mathrm{T}+\mathrm{T} / \mathrm{T}$ & 30 & (29) & 33 & $(28)$ & 37 & (29) & & & \\
\hline \multicolumn{10}{|l|}{ Heterozygote } \\
\hline $\mathrm{C} / \mathrm{T}$ & 30 & (29) & 31 & $(26)$ & 37 & (29) & \multirow{2}{*}{0.963} & \multirow{2}{*}{0.751} & \multirow{2}{*}{0.742} \\
\hline $\mathrm{C} / \mathrm{C}+\mathrm{T} / \mathrm{T}$ & 72 & $(71)$ & 86 & $(74)$ & 90 & $(71)$ & & & \\
\hline \multicolumn{10}{|l|}{ Recessive } \\
\hline $\mathrm{T} / \mathrm{T}$ & - & $(0)$ & 2 & (2) & - & $(0)$ & \multirow{2}{*}{-} & \multirow{2}{*}{ - } & \multirow{2}{*}{-} \\
\hline $\mathrm{C} / \mathrm{T}+\mathrm{C} / \mathrm{C}$ & 102 & (100) & 115 & $(98)$ & 127 & (100) & & & \\
\hline $\mathrm{HW}\left(\chi^{2}\right)$ & \multicolumn{2}{|c|}{3.03} & \multicolumn{2}{|c|}{0.20} & \multicolumn{2}{|c|}{3.69} & \multicolumn{3}{|c|}{$>0.05$} \\
\hline
\end{tabular}

(b) Al154G

\begin{tabular}{|c|c|c|c|c|c|c|c|c|c|}
\hline \multirow[b]{3}{*}{ Allele } & \multicolumn{2}{|c|}{$\mathrm{G} 1(N=102)$} & \multicolumn{2}{|c|}{$\mathrm{G} 2(N=117)$} & \multicolumn{2}{|c|}{$\mathrm{G} 3(N=217)$} & \multicolumn{3}{|c|}{$P^{*}$ value } \\
\hline & & & & & & & \multirow{2}{*}{$\mathrm{G} 1 \times \mathrm{G} 3$} & \multirow{2}{*}{$\mathrm{G} 2 \times \mathrm{G} 3$} & \multirow{2}{*}{$\mathrm{G} 1 \times \mathrm{G} 2$} \\
\hline & $n$ & $\mathrm{AF}$ & $n$ & $\mathrm{AF}$ & $n$ & $\mathrm{AF}$ & & & \\
\hline G & 157 & 0.77 & 172 & 0.74 & 193 & 0.76 & \multirow{2}{*}{0.893} & \multirow{2}{*}{0.598} & \multirow{2}{*}{0.469} \\
\hline A & 47 & 0.23 & 62 & 0.26 & 61 & 0.24 & & & \\
\hline Genotype & $N$ & $(\%)$ & $N$ & $(\%)$ & $N$ & $(\%)$ & & & \\
\hline \multicolumn{10}{|l|}{ Dominant } \\
\hline G/G & 61 & $(60)$ & 60 & $(51)$ & 73 & (57) & \multirow{2}{*}{0.826} & \multirow{2}{*}{0.399} & \multirow{2}{*}{0.258} \\
\hline $\mathrm{G} / \mathrm{A}+\mathrm{A} / \mathrm{A}$ & 41 & $(40)$ & 57 & (49) & 54 & (43) & & & \\
\hline \multicolumn{10}{|l|}{ Heterozygote } \\
\hline $\mathrm{G} / \mathrm{A}$ & 35 & $(34)$ & 52 & $(44)$ & 47 & (37) & \multirow{2}{*}{0.776} & \multirow{2}{*}{0.293} & \multirow{2}{*}{0.164} \\
\hline $\mathrm{A} / \mathrm{A}+\mathrm{G} / \mathrm{G}$ & 67 & $(66)$ & 65 & $(56)$ & 80 & (63) & & & \\
\hline \multicolumn{10}{|l|}{ Recessive } \\
\hline $\mathrm{A} / \mathrm{A}$ & 6 & $(6)$ & 5 & $(4)$ & 7 & (6) & \multirow{2}{*}{0.904} & \multirow{2}{*}{0.880} & \multirow{2}{*}{0.815} \\
\hline $\mathrm{G} / \mathrm{A}+\mathrm{G} / \mathrm{G}$ & 96 & (94) & 112 & (96) & 120 & (94) & & & \\
\hline $\mathrm{HW}\left(\chi^{2}\right)$ & \multicolumn{2}{|c|}{0.74} & \multicolumn{2}{|c|}{2.32} & \multicolumn{2}{|c|}{0.02} & & $>0.05$ & \\
\hline
\end{tabular}

${ }^{*}$ Fisher's exact test or Chi-Square test $\left(\chi^{2}\right) ; N=$ number of subjects; $n=$ number of alleles; AF = absolute frequency; HW = Hardy-Weinberg.

G2 showed area under the curve of $0.80(0.60-1.0)$, with $63 \%$ of sensitivity and $93 \%$ of specificity for cut-off of $311.8 \mathrm{pg} / \mathrm{mL}$. The comparison of G1 versus G3 for the same polymorphism showed an area under the curve 0.89 (0.611.0 ), with $75 \%$ of sensitivity and $100 \%$ of specificity for the cut-off of $225.5 \mathrm{pg} / \mathrm{mL}$. VEGF-A1154G analysis of G1 versus G2 showed an area under the curve of $0.76(0.60-0.92)$, with sensitivity of $76 \%$ and specificity of $65 \%$ for the cut-off of $222.1 \mathrm{pg} / \mathrm{mL}$.

\section{Discussion}

This study evaluated demographic profile, lifestyle, comorbidities, and clinical classification of patients with HCC and their association with $V E G F-A$ polymorphisms, a key angiogenic factor in the development of HCC [12]. Men prevailed among patients, in agreement with global estimates (71\%) [3]. Alcohol consumption prevailed among patients with HCC and those with cirrhosis, compared with controls. The association between chronic liver diseases and alcohol consumption is well established [23, 24]. Alcohol intake causes damage to the liver tissue, due to the action of endotoxins, oxidative stress, and inflammation, causing fibrosis in the hepatic tissue, which contributes to the development of cirrhosis and HCC [25]. There was a higher frequency of smoking among patients with HCC, in agreement with another study that compared such association with the exposure to mutagenic and carcinogenic components [26]. 

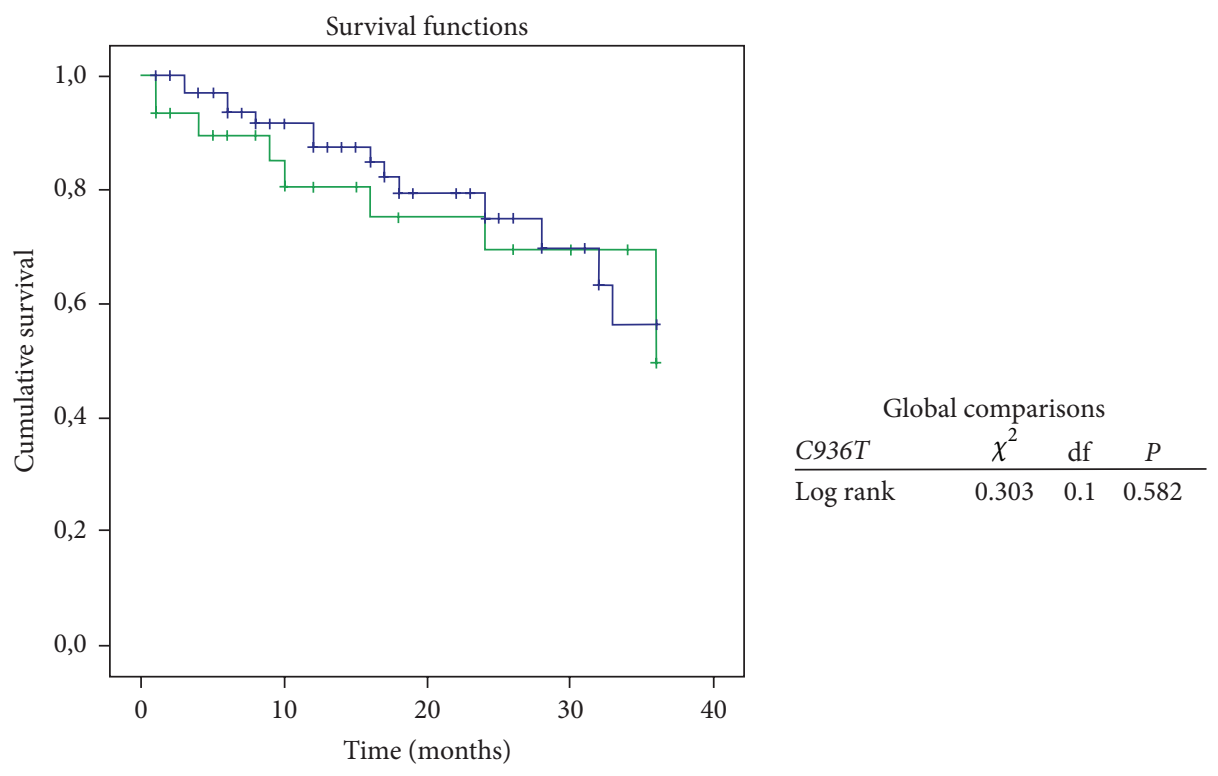

VEGF-C936T

$$
\begin{array}{ll}
\neg 0 & +0 \text {-censored } \\
\neg 1 & +1 \text {-censored }
\end{array}
$$

(a)

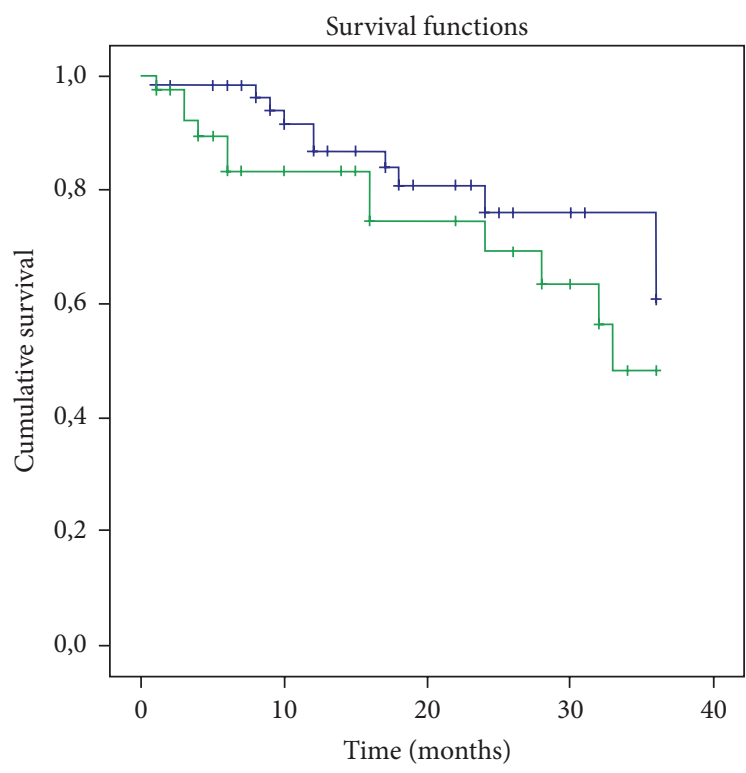

$$
\begin{array}{lccc}
\multicolumn{5}{c}{\text { Global comparisons }} \\
\text { A1154G } & \chi^{2} & \text { df } & P \\
\hline \text { Log rank } & 1.752 & 1 & 0.186
\end{array}
$$

VEGF-A1154G

$$
\neg 0 \quad+0 \text {-censored }
$$

(b)

FIGURE 1: Kaplan-Meier curve for overall survival analysis of patients with hepatocellular carcinoma after 36 months of diagnosis. (a) VEGFC936T: 1 = genotype C/T, 0 = genotype C/C; (b) VEGF-A1154G: 1 = genotypes $\_/ A, 0$ = genotype G/G; df = degree of freedom.

Prevalence of cirrhosis in HCC patients was also observed in this study, followed by HCV and HBV, consistent with an epidemiological study, whose frequencies varied between 80 and $90 \%$ for cirrhosis and 44 and $66 \%$ for HCV in HCC cases, but indicated the presence of HBV in $50 \%$ of patients [27]. The lowest HBV index in this study can be explained by increased access of this population to immunizations, compared with the world population, especially in Asia and Africa, where HBV infection is highly endemic [28].

The studied polymorphisms are located in the promoter region of VEGF-A (A1154G) and $3^{\prime}$-UTR (C936T). The $3^{\prime}$ UTR region of the gene contains key regulatory elements 
TABLE 3: Allelic and genotypic frequencies of VEGF-C936T and VEGF-A1154G polymorphisms in patients with hepatocellular carcinoma (G1), considering the BCLC clinical classification.

(a) $\mathrm{C} 936 \mathrm{~T}$

\begin{tabular}{|c|c|c|c|c|c|c|c|c|c|}
\hline \multirow{3}{*}{$\begin{array}{l}\text { VEGF } \\
\text { Allele }\end{array}$} & \multicolumn{6}{|c|}{ BCLC: 89 patients } & \multicolumn{3}{|c|}{$P^{*}$ value } \\
\hline & \multicolumn{2}{|c|}{$\mathrm{A}(N=28)$} & \multicolumn{2}{|c|}{$\mathrm{B} / \mathrm{C}(N=52)$} & \multicolumn{2}{|c|}{$\mathrm{D}(N=9)$} & \multirow[t]{2}{*}{$\mathrm{A} \times \mathrm{B} / \mathrm{C}$} & \multirow[t]{2}{*}{$\mathrm{A} \times \mathrm{D}$} & \multirow[t]{2}{*}{$\mathrm{B} / \mathrm{C} \times \mathrm{D}$} \\
\hline & $n$ & $\mathrm{AF}$ & $n$ & $\mathrm{AF}$ & $n$ & $\mathrm{AF}$ & & & \\
\hline $\mathrm{C}$ & 48 & 0.86 & 88 & 0.85 & 16 & 0.89 & \multirow{2}{*}{1.000} & \multirow{2}{*}{1.000} & \multirow{2}{*}{1.000} \\
\hline $\mathrm{T}$ & 8 & 0.14 & 16 & 0.15 & 2 & 0.11 & & & \\
\hline Genotype & $N$ & $(\%)$ & $N$ & $(\%)$ & $N$ & $(\%)$ & & & \\
\hline $\mathrm{C} / \mathrm{C}$ & 20 & (71) & 36 & (69) & 7 & (78) & \multirow{2}{*}{1.000} & \multirow{2}{*}{1.000} & \multirow{2}{*}{0.7131} \\
\hline $\mathrm{C} / \mathrm{T}$ & 8 & (29) & 16 & $(31)$ & 2 & (22) & & & \\
\hline $\mathrm{T} / \mathrm{T}$ & 0 & $(0)$ & 0 & (0) & 0 & $(0)$ & - & - & - \\
\hline
\end{tabular}

(b) A1154

\begin{tabular}{|c|c|c|c|c|c|c|c|c|c|}
\hline \multirow{3}{*}{$\begin{array}{l}\text { VEGF } \\
\text { Allele } \\
\end{array}$} & \multicolumn{6}{|c|}{ BCLC: 89 patients } & \multicolumn{3}{|c|}{$P^{*}$ value } \\
\hline & \multicolumn{2}{|c|}{$\mathrm{A}(N=28)$} & \multicolumn{2}{|c|}{$\mathrm{B} / \mathrm{C}(N=52)$} & \multicolumn{2}{|c|}{$\mathrm{D}(N=9)$} & \multirow[t]{2}{*}{$\mathrm{A} \times \mathrm{B} / \mathrm{C}$} & \multirow[t]{2}{*}{$\mathrm{A} \times \mathrm{D}$} & \multirow[t]{2}{*}{$\mathrm{B} / \mathrm{C} \times \mathrm{D}$} \\
\hline & $n$ & $\mathrm{AF}$ & $n$ & $\mathrm{AF}$ & $n$ & $\mathrm{AF}$ & & & \\
\hline G & 41 & 0.73 & 83 & 0.80 & 14 & 0.78 & \multirow{2}{*}{0.4508} & \multirow{2}{*}{1.000} & \multirow{2}{*}{0.7623} \\
\hline $\mathrm{A}$ & 15 & 0.27 & 21 & 0.20 & 4 & 0.22 & & & \\
\hline Genotype & $N$ & $(\%)$ & $N$ & $(\%)$ & $N$ & $(\%)$ & & & \\
\hline $\mathrm{G} / \mathrm{G}$ & 14 & $(50)$ & 35 & (67) & 5 & (56) & 0.2023 & 1.000 & 0.7056 \\
\hline $\mathrm{A} / \mathrm{G}$ & 13 & $(46)$ & 13 & (25) & 4 & $(44)$ & 0.0888 & 1.000 & 0.2489 \\
\hline $\mathrm{A} / \mathrm{A}$ & 1 & $(4)$ & 4 & $(8)$ & 0 & $(0)$ & 0.6525 & - & - \\
\hline
\end{tabular}

${ }^{*}$ Fisher's exact test or Chi-Square test with Yates correction; BCLC = Barcelona Clinic Liver Cancer; VEGF = vascular endothelial growth factor; $N=$ number of subjects; $n=$ number of alleles; $\mathrm{AF}=$ absolute frequency.

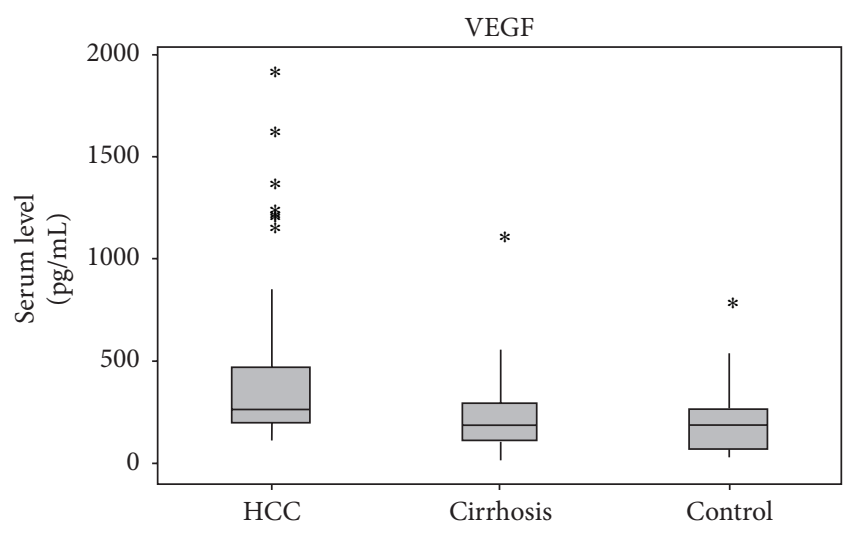

FIGURE 2: Box-plot representation of median and quartile values of serum vascular endothelial growth factor (VEGF) levels. HCC: median $=264.8$, minimum $=102.0$, maximum $=1795.1, \mathrm{Q} 1=$ 199.4, Q3 = 467.7, and IQRange $=268.3$; cirrhosis: median $=182.8$, minimum $=7.2$, maximum $=993.0, \mathrm{Q} 1=103.9, \mathrm{Q} 3=287.4$, and IQRange $=183.5$; control: median $=182.2$, minimum $=31.6$, maximum $=666.1, \mathrm{Q} 1=66.14, \mathrm{Q} 3=265.5$, and IQRange $=199.4$. * Extreme outliers of the distribution of serum levels values. Extreme outliers are observations that are beyond one of the outer fence OF1 or OF2. The outer fences are calculated as follows: OF1 $=\mathrm{Q} 1-3 *$ $\mathrm{IQR}, \mathrm{OF} 2=\mathrm{Q} 3+3 * \mathrm{IQR}$.

which are sensitive to hypoxia (condition that stimulates the expression of VEGF) and contributes to high variability in VEGF production among tissues [29]. Related to the promoter region of the gene, in vitro study showed that mutations in this region regulate the expression of the gene in peripheral blood mononuclear cells, suggesting that the regulation of VEGF expression occurs primarily at transcriptional level [30].

VEGF-C936T and VEGF-A1154G are polymorphisms located in an important angiogenesis signalling pathway related to the development and prognosis of HCC, a wellvascularized solid tumour which depends on neovascularization for its growth [31]. In this case, the relationship between the respective mutant alleles and decreased expression and plasma levels of VEGF has been reported [17, 18], which may be a protective factor against the development of HCC. However, this study did not find an association of VEGFC936T as well as VEGF-A1154G with cirrhosis or HCC. There are reports of these polymorphisms in susceptibility to HCC in Italian and Chinese populations, which may also suggest a relationship between ethnicity and VEGF variants [16, 20].

Analysis of the survival curve considering VEGF-A1154G and VEGF-C936T polymorphisms was performed, showing decreased survival, although without significance, in the presence of the mutant allele for both polymorphisms. These findings agreed with another study that showed an association of the homozygous mutant genotype VEGF-A1154G with increased risk of death for HCC [32]. However, the small sample size may have been a limiting factor in the present study.

Although studies about the association between VEGF polymorphisms and survival in HCC are scarce, its influence 
TABLE 4: Quantitative analysis of allelic and genotypic frequencies of VEGF-C936T and VEGF-A1154G polymorphisms in patients with hepatocellular carcinoma (G1), cirrhosis (G2), and controls (G3), considering serum levels of VEGF.

(a) VEGF-C936T

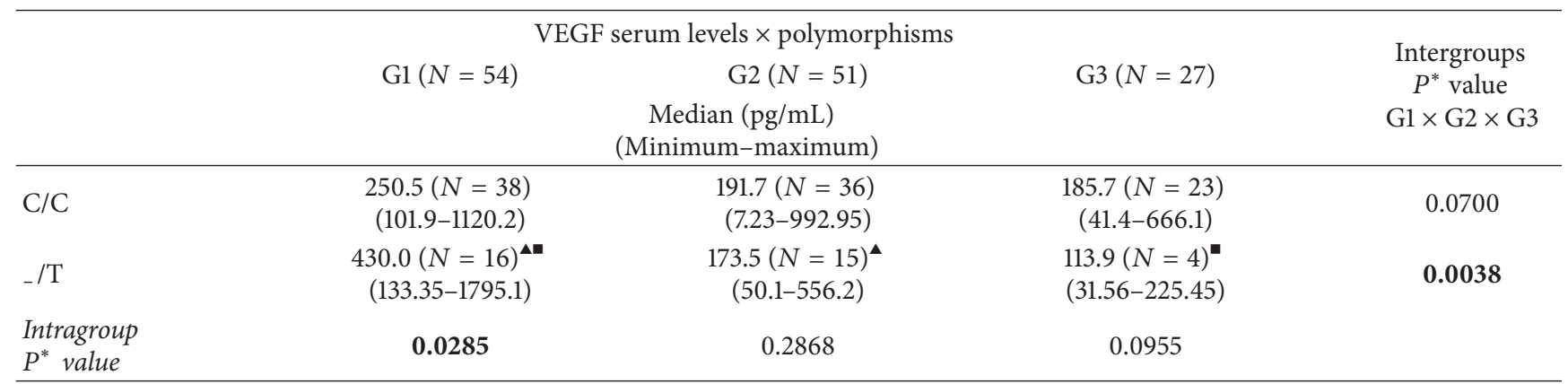

(b) VEGF-A1154G

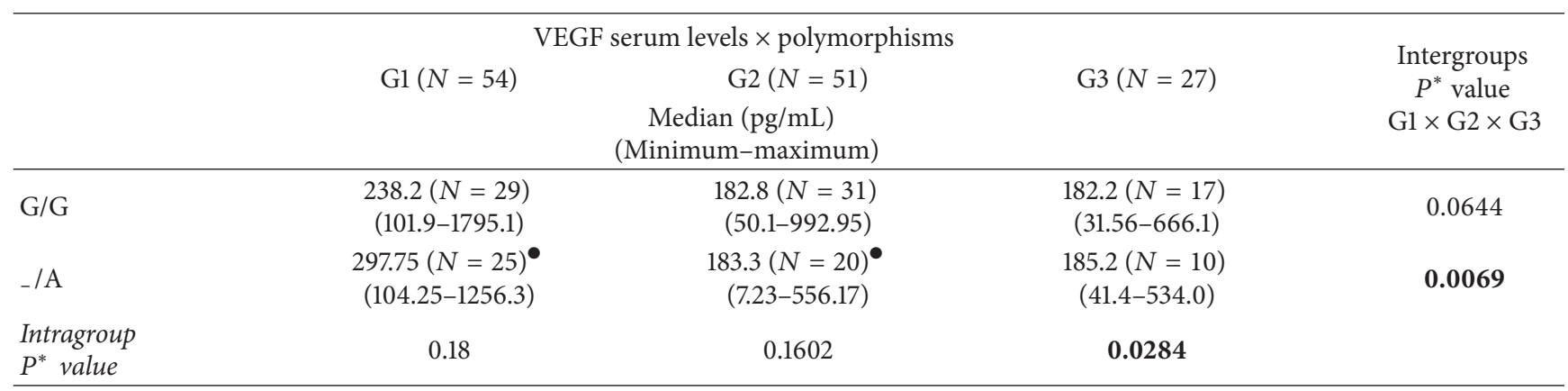

${ }^{*}$ Mann-Whitney and Kruskal-Wallis tests for intragroup and intergroup analyses, respectively; VEGF = vascular endothelial growth factor; $N=$ number of subjects; $\boldsymbol{\Lambda}$ and $\mathbf{m}: P<0.05 ; \bullet: P<0.01$.

on other types of cancer, such as colorectal and oesophagus, is recognised [33, 34]. Furthermore, the wild-type allele of VEGF-A1154G polymorphism was associated with poor survival in a Caucasian population with oral squamous cell carcinoma [35]. But the results are still diverging [3639]. Increased serum levels of VEGF could only be observed in the HCC group, compared with the group with cirrhosis and controls, in agreement with a study by Mukozu et al. [40]. In this case, emphasis should be given to the relationship between VEGF and neovascularization and cell proliferation, both related to carcinogenesis, demonstrating the predictive value of VEGF for HCC. Analysis of serum VEGF levels according to the studied polymorphisms showed significant association between mutant alleles of both polymorphisms and increased serum VEGF levels, in agreement with a study, which showed the relationship between the mutant genotype of A1154G with poor prognosis in patients with HCC [41]. On the other hand, there are studies in which the mutant allele of VEGF-C936T was associated with decreased serum VEGF levels $[15,19]$.

Additionally, increased serum level of VEGF was observed in patients with HCC, particularly in the presence of the mutant alleles, compared with patients with cirrhosis and controls. This association highlights the action of the gene to promote vascularization and cell proliferation [42, 43] and strengthens the relationship between VEGF mutation and its serum level, contributing to the development of the disease. Serum levels of VEGF have been studied as potential markers for HCC. El-Sherif et al. reported a sensitivity of $60 \%$ and specificity of $92 \%$ for cut-off of $268.0 \mathrm{pg} / \mathrm{mL}$ [44]. El-Houseini et al. found $86.4 \%$ of sensitivity and $60 \%$ of specificity for the cut-off of $355.2 \mathrm{pg} / \mathrm{mL}$ [45]. In this study, the association of serum VEGF levels with the mutant alleles of VEGF-A (C936T and A1154G) showed cut-off value of $225.5 \mathrm{pg} / \mathrm{mL}$, with specificity of $100 \%$ and sensitivity of $75 \%$ (C936T) comparing G1 and G3, conferring potential to serum VEGF levels in the diagnosis of HCC, which should be confirmed in numerous patient samples.

\section{Conclusion}

This study showed that VEGF-A polymorphisms (C936T and A1154G) are not associated with cirrhosis, HCC, and survival. However, there is a relationship between increased serum levels of VEGF and the presence of mutant alleles of both polymorphisms, which may contribute to the diagnosis and prognosis of HCC.

\section{Competing Interests}

The authors declare that there is no conflict of interests regarding the publication of this paper. 


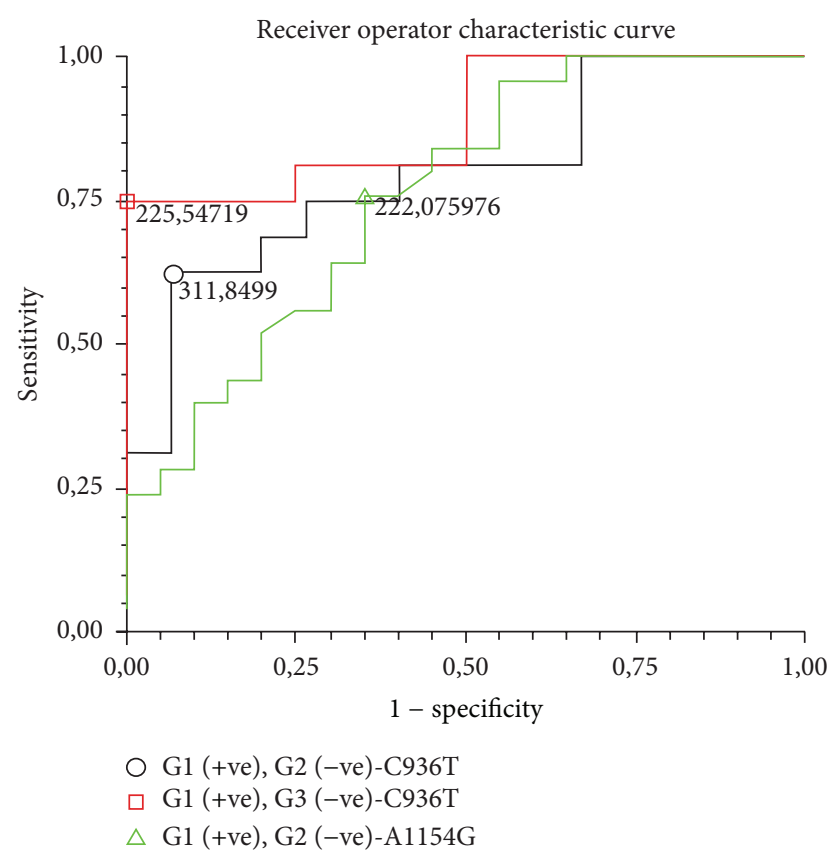

FIGURE 3: Receiver operator characteristic curve (ROC) of serum vascular endothelial growth factor (VEGF) levels in patients with (O) mutant allele of VEGF-C936T in the group with hepatocellular carcinoma (G1) and cirrhosis (G2) (area under the curve $=0.80$ [0.60-1.0]), with sensitivity of $63 \%$ and specificity of $93 \%$, to the cut-off value of $311.8 \mathrm{pg} / \mathrm{mL}$; ( $\square$ ) mutant allele of VEGF-C936T in G1 and controls (G3) (area under the curve $=0.89[0.60-1.0]$ ), with sensitivity of $75 \%$ and specificity of $100 \%$, to the cut-off value of $225.5 \mathrm{pg} / \mathrm{mL} ;(\triangle)$ mutant allele of VEGF-A1154G in G1 and G2 (area under the curve $=0.76[0.60-0.92])$, with sensitivity of $76 \%$ and specificity of $65 \%$, to the cut-off value of $222.1 \mathrm{pg} / \mathrm{mL}$.

\section{Acknowledgments}

The authors would like to thank Helen Catharine Camarero Felicio and Sabrina Mayara Cesario Gimenez for their technical support, which strongly facilitated the implementation of this study. They also thank the team at the Gastroenterology Clinic of HB University Medical Centre in São José do Rio Preto for their collaboration during selection and care of patients and the Research Support Foundation of the State of São Paulo (FAPESP) for the supporting grants (2012/19826$3)$.

\section{References}

[1] M. A. Gomes, D. N. Priolli, J. G. Tralhão, and M. F. Botelho, "Carcinoma hepatocelular: epidemiologia, biologia, diagnóstico e terapias," Revista da Associação Médica Brasileira, vol. 59, no. 5, pp. 514-524, 2013.

[2] World Health Organization, GLOBOCAN 2012: Estimated Cancer Incidence, Mortality and Prevalence Worldwide in 2012, 2014, http://globocan.iarc.fr.

[3] K. J. Lafaro, A. N. Demirjian, and T. M. Pawlik, "Epidemiology of hepatocellular carcinoma," Surgical Oncology Clinics of North America, vol. 24, no. 1, pp. 1-17, 2015.
[4] U. Asghar and T. Meyer, "Are there opportunities for chemotherapy in the treatment of hepatocellular cancer?" Journal of Hepatology, vol. 56, no. 3, pp. 686-695, 2012.

[5] J. Bruix and M. Sherman, "Management of hepatocellular carcinoma: an update," Hepatology, vol. 53, no. 3, pp. 1020-1022, 2011.

[6] A. M. Crissien and C. Frenette, "Current management of hepatocellular carcinoma," Gastroenterology and Hepatology, vol. 10, no. 3, pp. 153-161, 2014.

[7] A. Flores and J. A. Marrero, "Emerging trends in hepatocellular carcinoma: focus on diagnosis and therapeutics," Clinical Medicine Insights: Oncology, vol. 8, pp. 71-76, 2014.

[8] W.-L. Shih, H.-C. Chang, Y.-F. Liaw et al., "Influences of tobacco and alcohol use on hepatocellular carcinoma survival," International Journal of Cancer, vol. 131, no. 11, pp. 2612-2621, 2012.

[9] R. J. F. Felizardo and N. O. S. Câmara, "Hepatocellular carcinoma and food contamination: aflatoxins and ochratoxin A as great prompter," World Journal of Gastroenterology, vol. 19, no. 24, pp. 3723-3725, 2013.

[10] A. Moeini, H. Cornellà, and A. Villanueva, "Emerging signaling pathways in hepatocellular carcinoma," Liver Cancer, vol. 1, no. 2, pp. 83-93, 2012.

[11] M. Fernández, D. Semela, J. Bruix, I. Colle, M. Pinzani, and J. Bosch, "Angiogenesis in liver disease," Journal of Hepatology, vol. 50, no. 3, pp. 604-620, 2009.

[12] S. Coulon, F. Heindryckx, A. Geerts, C. Van Steenkiste, I. Colle, and H. Van Vlierberghe, "Angiogenesis in chronic liver disease and its complications," Liver International, vol. 31, no. 2, pp. 146162, 2011.

[13] X. Liang, F. Xu, X. Li, C. Ma, Y. Zhang, and W. Xu, "VEGF signal system: the application of antiangiogenesis," Current Medicinal Chemistry, vol. 21, no. 7, pp. 894-910, 2014.

[14] M. Shibuya, "VEGF-VEGFR signals in health and disease," Biomolecules and Therapeutics, vol. 22, no. 1, pp. 1-9, 2014.

[15] L. Jain, C. A. Vargo, R. Danesi et al., "The role of vascular endothelial growth factor SNPs as predictive and prognostic markers for major solid tumors," Molecular Cancer Therapeutics, vol. 8, no. 9, pp. 2496-2508, 2009.

[16] X. Wu, Z. Xin, W. Zhang et al., "Polymorphisms in the VEGFA promoter are associated with susceptibility to hepatocellular carcinoma by altering promoter activity," International Journal of Cancer, vol. 133, no. 5, pp. 1085-1093, 2013.

[17] R. Zhai, M. N. Gong, W. Zhou et al., "Genotypes and haplotypes of the VEGF gene are associated with higher mortality and lower VEGF plasma levels in patients with ARDS," Thorax, vol. 62 , no. 8, pp. 718-722, 2007.

[18] M. I. Koukourakis, D. Papazoglou, A. Giatromanolaki, G. Bougioukas, E. Maltezos, and E. Siviridis, "VEGF gene sequence variation defines VEGF gene expression status and angiogenic activity in non-small cell lung cancer," Lung Cancer, vol. 46, no. 3, pp. 293-298, 2004.

[19] W. Renner, S. Kotschan, C. Hoffmann, B. Obermayer-Pietsch, and E. Pilger, "A common $936 \mathrm{C} / \mathrm{T}$ mutation in the gene for vascular endothelial growth factor is associated with vascular endothelial growth factor plasma levels," Journal of Vascular Research, vol. 37, no. 6, pp. 443-448, 2000.

[20] A. Giacalone, G. Montalto, L. Giannitrapani et al., "Association between single nucleotide polymorphisms in the Cyclooxygenase-2, tumor necrosis factor- $\alpha$, and vascular endothelial growth factor-A genes, and susceptibility to hepatocellular carcinoma," OMICS, vol. 15, no. 3, pp. 193-196, 2011. 
[21] Ministério da Saúde (BR), "Ordinance no. 2.712, of 2013 November 12. Redefine o regulamento técnico de procedimentos hemoterápicos," Diário Oficial da União. Seção 1, 2013.

[22] L. A. Salazar, M. H. Hirata, S. A. Cavalli, M. O. Machado, and R. D. C. Hirata, "Optimized procedure for DNA isolation from fresh and cryopreserved clotted human blood useful in clinical molecular testing," Clinical Chemistry, vol. 44, no. 8, pp. 1748$1750,1998$.

[23] G. Testino, S. Leone, and P. Borro, "Alcohol and hepatocellular carcinoma: a review and a point of view," World Journal of Gastroenterology, vol. 20, no. 43, pp. 15943-15954, 2014.

[24] J. M. Crawford, "Histologic findings in alcoholic liver disease," Clinics in Liver Disease, vol. 16, no. 4, pp. 699-716, 2012.

[25] D. Fullwood, "Alcohol-related liver disease," Nursing Standard, vol. 28 , no. 46, pp. 42-47, 2014.

[26] V. Purohit, R. Rapaka, O. S. Kwon, and B. J. Song, "Roles of alcohol and tobacco exposure in the development of hepatocellular carcinoma," Life Sciences, vol. 92, no. 1, pp. 3-9, 2013.

[27] S. Mittal and H. B. El-Serag, "Epidemiology of HCC: consider the population," Journal of Clinical Gastroenterology, vol. 47, pp. S2-S6, 2013.

[28] World Health Organization, Hepatitis B: Fact Sheet, 2014, http://www.who.int/mediacentre/factsheets/fs204/en/.

[29] A. Minchenko, S. Salceda, T. Bauer, and J. Caro, "Hypoxia regulatory elements of the human vascular endothelial growth factor gene," Cellular and Molecular Biology Research, vol. 40, no. 1, pp. 35-39, 1994.

[30] M. Mohammadi, W. E. Ollier, and I. V. Hutchinson, "A functional association study of VEGF gene promoter polymorphisms with VEGF expression by stimulated pbm cells," Human Immunology, vol. 64, no. 10, article S125, 2003.

[31] A. O. Kaseb, A. Hanbali, M. Cotant, M. M. Hassan, I. Wollner, and P. A. Philip, "Vascular endothelial growth factor in the management of hepatocellular carcinoma: a review of literature," Cancer, vol. 115, no. 21, pp. 4895-4906, 2009.

[32] J. Song, L. Z. Wang, X. Li et al., "Polymorphisms of vascular endothelial growth factor on prognosis in hepatocellular carcinoma patients receiving transcatheter arterial chemoembolization treatment," Genetics and Molecular Research, vol. 13, no. 4, pp. 8946-8953, 2014.

[33] P. A. Bradbury, R. Zhai, C. Ma et al., "Vascular endothelial growth factor polymorphisms and esophageal cancer prognosis," Clinical Cancer Research, vol. 15, no. 14, pp. 4680-4685, 2009.

[34] M. Vidaurreta, R. Sánchez-Muñoz, S. Veganzones et al., "Vascular endothelial growth factor gene polymorphisms in patients with colorectal cancer," Revista Española de Enfermedades Digestivas, vol. 102, no. 1, pp. 20-31, 2010.

[35] G. Supic, N. Jovic, K. Zeljic, R. Kozomara, and Z. Magic, "Association of VEGF-A genetic polymorphisms with cancer risk and survival in advanced-stage oral squamous cell carcinoma patients," Oral Oncology, vol. 48, no. 11, pp. 1171-1177, 2012.

[36] T.-T. Hong, R.-X. Zhang, X.-H. Wu, and D. Hua, "Polymorphism of vascular endothelial growth factor $-1154 \mathrm{G}>\mathrm{A}$ (rs1570360) with cancer risk: a meta-analysis of 16 case-control studies," Molecular Biology Reports, vol. 39, no. 5, pp. 5283-5289, 2012.

[37] T. P. Lau, A. C. Roslani, L. H. Lian et al., "Association between EGF and VEGF functional polymorphisms and sporadic colorectal cancer in the Malaysian population," Genetics and Molecular Research, vol. 13, no. 3, pp. 5555-5561, 2014.
[38] J. A. Rinck-Junior, C. Oliveira, G. J. Lourenço et al., "Vascular endothelial growth factor (VEGF) polymorphism and increased risk of epithelial ovarian cancer," Journal of Cancer Research and Clinical Oncology, vol. 141, no. 1, pp. 69-73, 2015.

[39] Y. Yang, X. Zhang, D. Song, and J. Wei, “Association between vascular endothelial growth factor gene polymorphism and bladder cancer risk," Molecular and Clinical Oncology, vol. 2, no. 4, pp. 501-505, 2014.

[40] T. Mukozu, H. Nagai, D. Matsui, T. Kanekawa, and Y. Sumino, "Serum VEGF as a tumor marker in patients with HCVrelated liver cirrhosis and hepatocellular carcinoma," Anticancer Research, vol. 33, no. 3, pp. 1013-1021, 2013.

[41] S.-Y. Kong, J.-W. Park, A. L. Jung et al., "Association between vascular endothelial growth factor gene polymorphisms and survival in hepatocellular carcinoma patients," Hepatology, vol. 46, no. 2, pp. 446-455, 2007.

[42] E. G. Yegin, A. Siykhymbayev, F. Eren, N. Bekiroglu, and O. C. Ozdogan, "Prognostic implication of serum vascular endothelial growth factor in advanced hepatocellular carcinoma staging," Annals of Hepatology, vol. 12, no. 6, pp. 915-925, 2013.

[43] P. Zhan, Q. Qian, and L.-K. Yu, "Serum VEGF level is associated with the outcome of patients with hepatocellular carcinoma: a meta-analysis," Hepatobiliary Surgery and Nutrition, vol. 2, no. 4, pp. 209-215, 2013.

[44] W. T. El-Sherif, N. A. Makhlouf, S. S. El-Gendi, H. I. Hassan, and O. M. Herdan, "Evaluation of transforming growth factor alpha and vascular endothelial growth factor in diagnosis of hepatocellular carcinoma," The Egyptian Journal of Immunology, vol. 19, no. 2, pp. 53-65, 2012.

[45] M. E. El-Houseini, M. S. Mohammed, W. M. Elshemey, T. D. Hussein, O. S. Desouky, and A. A. Elsayed, "Enhanced detection of hepatocellular carcinoma," Cancer Control, vol. 12, no. 4, pp. 248-253, 2005. 


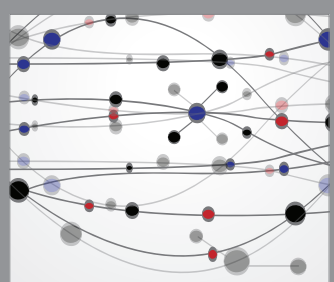

The Scientific World Journal
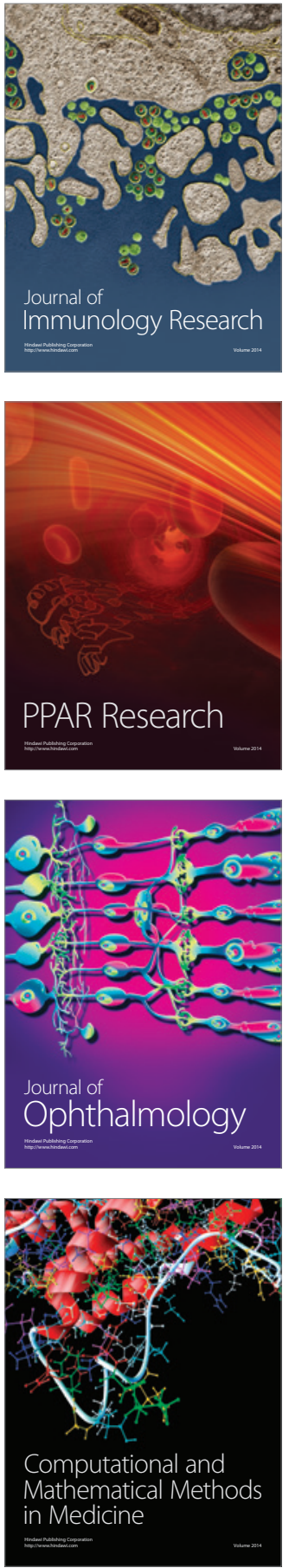

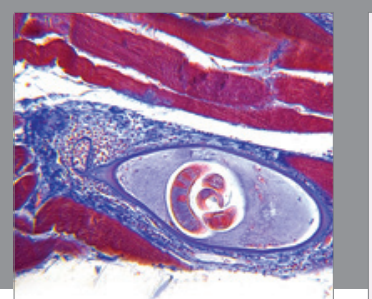

Gastroenterology Research and Practice

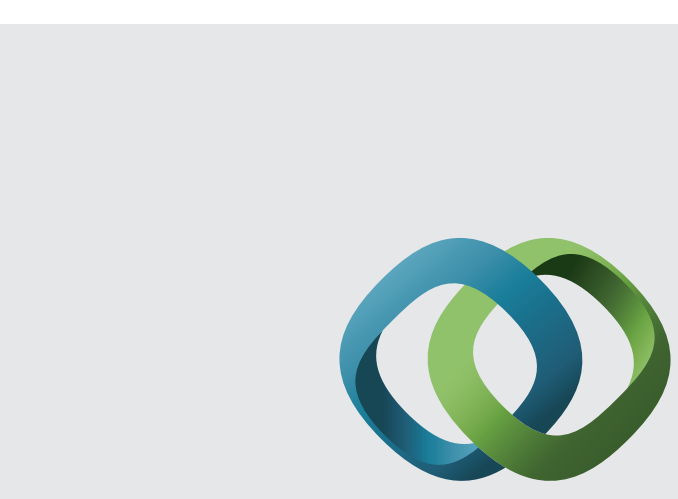

\section{Hindawi}

Submit your manuscripts at

http://www.hindawi.com
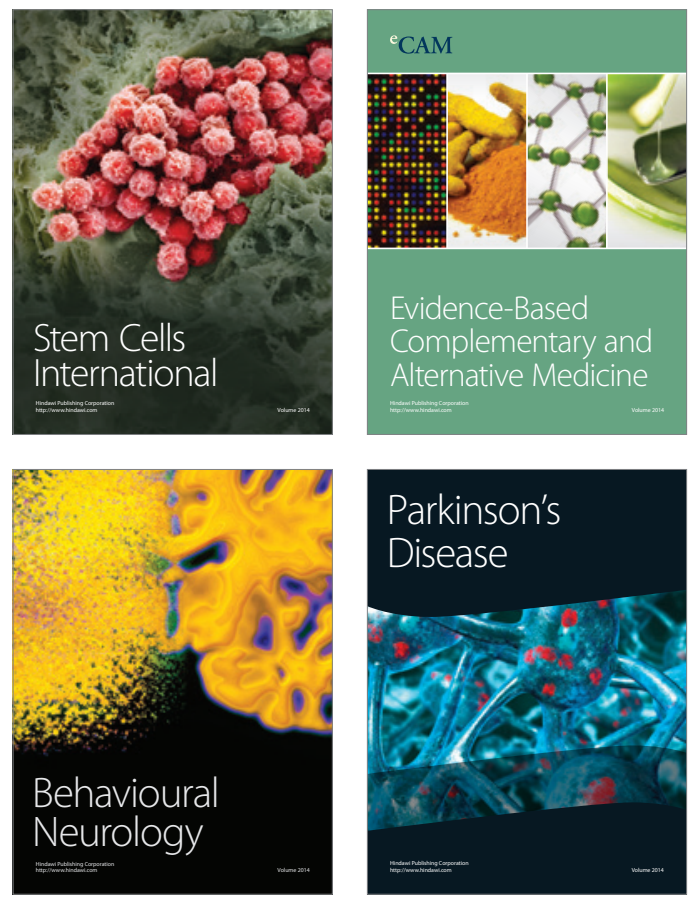
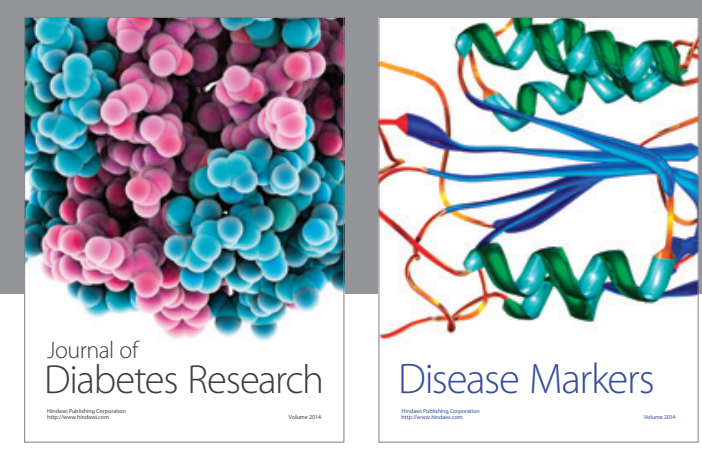

Disease Markers
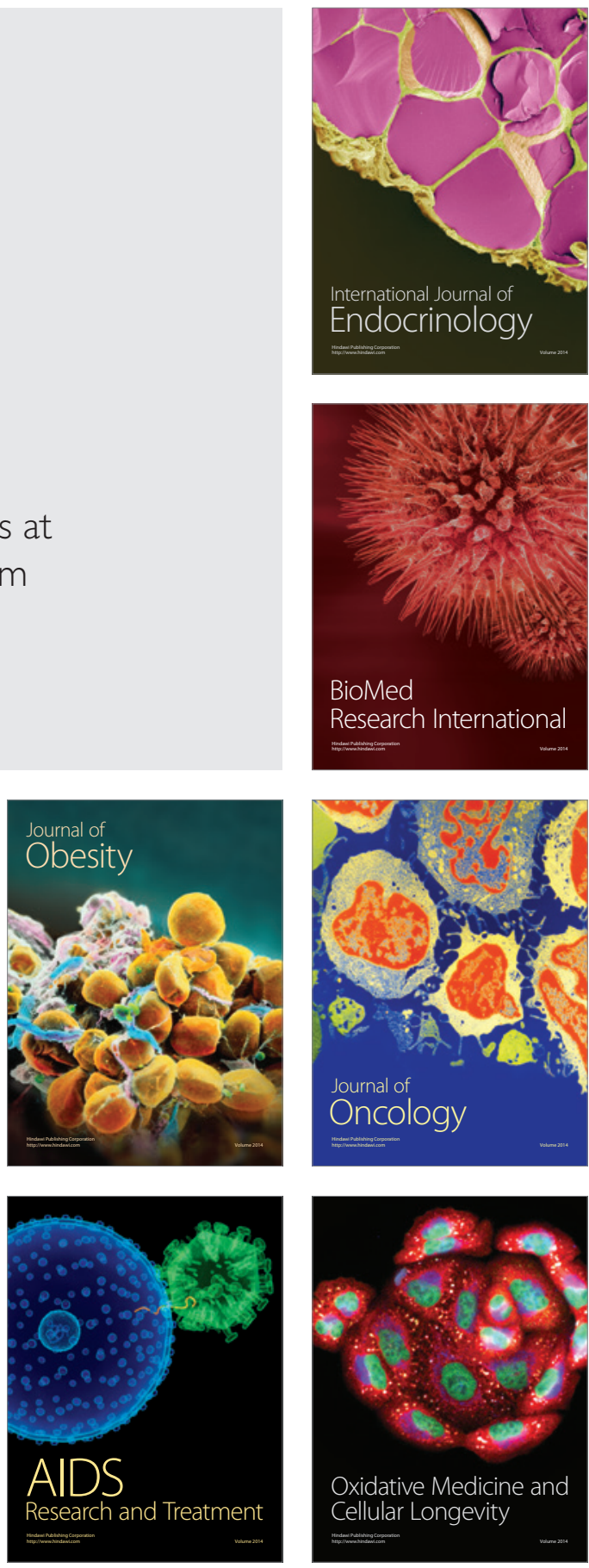